\title{
Plasma-catalytic Oxidation of Toluene on Ag Modified $\mathrm{FeO}_{x} / \mathrm{SBA}-15$
}

\author{
Meijuan Lu',2, Wenting Yang ${ }^{3}$, Chenglong Yu', Qian $\mathrm{Liu}^{4}$, Daiqi Ye ${ }^{2 *}$ \\ ${ }^{1}$ School of Environmental and Land Resource Management, Jiangxi Agricultural University, Nanchang 330045, China \\ ${ }^{2}$ College of Environment and Energy, South China University of Technology, Guangzhou 510006, China \\ ${ }^{3}$ School of Agricultural Sciences, Jiangxi Agricultural University, Nanchang 330045, China \\ ${ }^{4}$ School of Sciences, Jiangxi Agricultural University, Nanchang 330045, China
}

\begin{abstract}
Catalysts created by loading $\mathrm{FeO}_{x}$ and $\mathrm{AgO}_{x}$ on $\mathrm{SBA}-15$ surfaces via wet impregnation were used to remove toluene with the assistance of non-thermal plasma (NTP). The catalysts were characterized with X-ray diffraction (XRD), scanning electron microscopy (SEM), and $\mathrm{H}_{2}$ temperature-programmed reduction $\left(\mathrm{H}_{2}-\mathrm{TPR}\right)$. The results showed that incorporating the SBA-15, $3 \% \mathrm{FeO}_{x} / \mathrm{SBA}-15$ and $2 \% \mathrm{FeO}_{x}-1 \% \mathrm{AgO}_{y} / \mathrm{SBA}-15$ catalysts enhanced the toluene removal efficiency and $\mathrm{CO}_{2}$ selectivity of the NTP system. The silver particles tended to cover the catalyst surface in the form of $\mathrm{Ag}_{\mathrm{g}} \mathrm{and} \mathrm{Ag}_{2} \mathrm{O}$, which lengthened the residual time of toluene in the NTP-catalytic system, thereby promoting the reaction of toluene with oxygen on the catalyst surface. Simultaneously, introducing Ag improved the distribution of $\mathrm{FeO}_{x}$ on the catalyst surface, increasing toluene oxidation and catalyst stability. According to our analysis of the toluene removal efficiency, identification of organic byproducts, and in situ FT-IR spectroscopy of the toluene adsorption, $\mathrm{FeO}_{x}$ and $\mathrm{AgO}_{x}$ significantly enhance the efficiency of toluene degradation in plasma-assisted catalytic systems.
\end{abstract}

Keywords: $\mathrm{FeO}_{x}-\mathrm{AgO}_{y} / \mathrm{SBA}-15$ catalyst; Toluene removal; Plasma-catalytic oxidation.

\section{INTRODUCTION}

Non-thermal plasma (NTP) combined catalysis technology is a promising method for VOCs oxidation due to its high economy and energy efficiency (Stasiulaitiene et al., 2016; $\mathrm{Lu}$ et al., 2019). At the same time, the $\mathrm{FeO}_{x}$ shows the outstanding performance for toluene removal in the NTP system. However, $\mathrm{CO}$ and other byproducts are formed during toluene degradation, and $\mathrm{CO}_{2}$ selectivity is low ( $\mathrm{Lu}$ et al., 2015). In order to overcome these disadvantages, the catalysts of bimetallic materials have been applied for VOCs degradation due to their prominent catalytic activity (Jiang et al., 2016; Zhu et al., 2016; Jiang et al., 2019). Noblemetal-based catalysts, such as $\mathrm{Pt}, \mathrm{Au}$, are traditional catalysts for the VOCs oxidation at low temperatures (Li et al., 2016; Yang et al., 2016). However, these pure noble metal catalysts also have some disadvantages, especially their high cost. Scirè et al. (2001) report that Ag could weaken the Fe-O bond, increase the mobility of the lattice oxygen, and thus improve the VOCs oxidation. Meanwhile, Ag has exceptional activity and is more economical (Jiang et al., 2016; Pangilinan

\footnotetext{
${ }^{*}$ Corresponding author.

Tel.: +86 20 39380516; Fax: +862039380518

E-mail address: cedqye@scut.edu.cn
}

et al., 2016). In addition, Ag could work as an adsorption center, improving adsorption ability and oxidation for VOCs (Chen et al., 2011; Huang et al., 2015). However, there has been little research in regards to combining this bimetallic oxide catalyst with NTP for VOCs degradation in the present literatures. Besides that, the effect of bimetallic catalyst on VOCs degradation in NTP system is still not clear. Therefore, we incorporated $\mathrm{Ag}$ into the $\mathrm{FeO}_{x}$ catalyst on account of the characteristics of these two materials, and co-loaded them on the surface of SBA-15 which has uniform mesoporous channels, high specific surface area, and high adsorption ability for toluene (Zhang et al., 2012b; Qin et al., 2019).

In this work, toluene was selected as the targeted pollutant, and the plasma-catalytic oxidization was carried out at identical specific energy density (SIE) under the condition of atmospheric pressure and room temperature. In order to study the structure and possible interaction between $\mathrm{FeO}_{x}$ and $\mathrm{AgO}_{y}$ species, the catalysts were characterized by XRD, SEM and $\mathrm{H}_{2}$-TPR. In situ FT-IR spectroscopy of toluene adsorption and organic byproducts on catalyst surface were also identified to acquire the toluene oxidation mechanism on the surface of $\mathrm{FeO}_{x}-\mathrm{AgO}_{y} / \mathrm{SBA}-15$ catalyst.

\section{EXPERIMENT}

\section{Experimental Setup}

The schematic diagram of the experimental setup is 
shown in Fig. 1. The toluene was obtained by bubbling liquid toluene with an $\mathrm{N}_{2}$ gas stream in a bubbler, which was described in our previous study (Lu et al., 2015). Then, the reaction gas was introduced into the reactor with an initial toluene concentration of $100 \mathrm{ppm}$ at a flow rate of

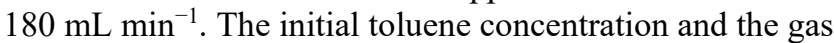
flow rate were adjusted by mass flow controllers (MFCs) (Seven Star Co., China).

Toluene oxidation was carried out in a fixed-bed flow reactor containing $0.12 \mathrm{~g}$ of the catalyst (40-60 mesh) and $0.96 \mathrm{~g}$ of silica sand (40-60 mesh). The outgoing gas was analyzed using an online gas chromatograph (GC2014C; Shimadzu) equipped with two FID detectors: one for organic compounds, featuring a TG-BOND Q column $(30 \mathrm{~m}, 0.32 \mathrm{~mm}$; $60^{\circ} \mathrm{C}$ ), and the other, equipped with a methanizer, for carbon monoxide and carbon dioxide analysis using a 5 A molecular sieve $(2 \mathrm{~m}, 2 \mathrm{~mm})$ and PoraPLOT Q column (4 m, $2 \mathrm{~mm})$ $\left(60^{\circ} \mathrm{C}\right)$. The toluene removal efficiency and $\mathrm{CO}_{2}$ selectivity were calculated based on the following formulas:

Toluene removal efficiency $(\%)=\frac{C_{\text {in }}-C_{\text {out }}}{C_{\text {in }}} \times 100 \%$

$\mathrm{CO}_{2}$ selectivity $(\%)=\frac{C_{\mathrm{CO}_{2}}}{7\left(C_{\mathrm{in}}-C_{\text {out }}\right)} \times 100 \%$

where $\mathrm{C}_{\mathrm{in}}$ and $\mathrm{C}_{\text {out }}$ are the inlet and outlet toluene concentrations respectively, $\mathrm{C}_{\mathrm{CO}_{2}}$ is the outlet concentration of $\mathrm{CO}_{2}$. All concentrations were measured in ppm, and the data was recorded by an online gas chromatograph when the toluene removal efficiency was stabilized.

\section{Plasma System}

The reactor was a cylinder reactor of quartz glass, with an inner diameter of $8 \mathrm{~mm}$ and wall thickness of $1 \mathrm{~mm}$. The stainless steel wire mesh was wrapped as the ground electrode, and a stainless steel rod (o.d. $=2 \mathrm{~mm}$ ) was used as the inner electrode, resulting in the discharge length and discharge gap being $18 \mathrm{~mm}$ and $3 \mathrm{~mm}$. The reactor was powered by an AC high-voltage power supplying with the frequency of $2 \mathrm{kHz}$ (CTP-2000k; Corona Laboratory, Nanjing, China). In the experiment, the discharge power was measured by the areas of the voltage-charge Lissajous figures, which were acquired by an oscilloscope (TDS1002; Tektronix) (Li et al., 2014).

The specific energy density (SED) was calculated from the following expression:

$\operatorname{SED}\left(\mathrm{J} \mathrm{L}^{-1}\right)=\frac{\text { Discharge power }(\mathrm{W})}{\text { Gas flow rate }\left(\mathrm{L} \mathrm{s}^{-1}\right)}$

\section{Catalyst Preparation and Characterization}

The catalysts were prepared using wetness impregnation method. Iron nitrate ethanol solution (Fe/SBA-15 $=2 \% \mathrm{wt}$. and $3 \% \mathrm{wt}$.) was first added to SBA-15 powder, after being stirred at room temperature for $24 \mathrm{~h}$, the solvent was then removed by evaporation at $60^{\circ} \mathrm{C}$. The residue was dried at $120^{\circ} \mathrm{C}$ for $12 \mathrm{~h}$, calcined at $500^{\circ} \mathrm{C}$ for $4 \mathrm{~h}$. The resulting catalysts were denoted as $2 \% \mathrm{FeO}_{x} / \mathrm{SBA}-15,3 \% \mathrm{FeO}_{x} / \mathrm{SBA}-15$, respectively. After that, Ag was loaded on the catalyst of $2 \% \mathrm{FeO}_{x} / \mathrm{SBA}-$ 15 using a similar process under the same condition with $\mathrm{AgNO}_{3}$ solutions as precursors $(\mathrm{Ag} / \mathrm{SBA}-15=1 \%$ wt. $)$. The resulting catalyst was denoted as $2 \% \mathrm{FeO}_{x}-1 \% \mathrm{AgO}_{y} / \mathrm{SBA}-15$.

XRD results were collected using a D8 ADVANCE X-ray diffractometer (Bruker, Germany) operated at $40 \mathrm{kV}$ and $40 \mathrm{~mA}$ using Ni-filtered $\mathrm{Cu} \mathrm{K} \alpha$ radiation, the $2 \theta$ ranges were $0.6-5^{\circ}$ and $5-90^{\circ}$ at a scanning rate of $4^{\circ} \mathrm{min}^{-1}$.

SEM microphotographs were collected with an S-3700N electron microscope (Hitachi, Japan) operating at $5.0 \mathrm{kV}$. $\mathrm{H}_{2}$-TPR data was collected by a Micromeritics AutoChem II 2920 instrument. Each catalyst $(40 \mathrm{mg})$ was pretreated at $300^{\circ} \mathrm{C}$ in the high-purity $\mathrm{Ar}\left(30 \mathrm{~mL} \mathrm{~min}^{-1}\right)$ for $30 \mathrm{~min}$ and then cooled to $60^{\circ} \mathrm{C}$. Subsequently, the flow of an $\mathrm{H}_{2}-\mathrm{Ar}$

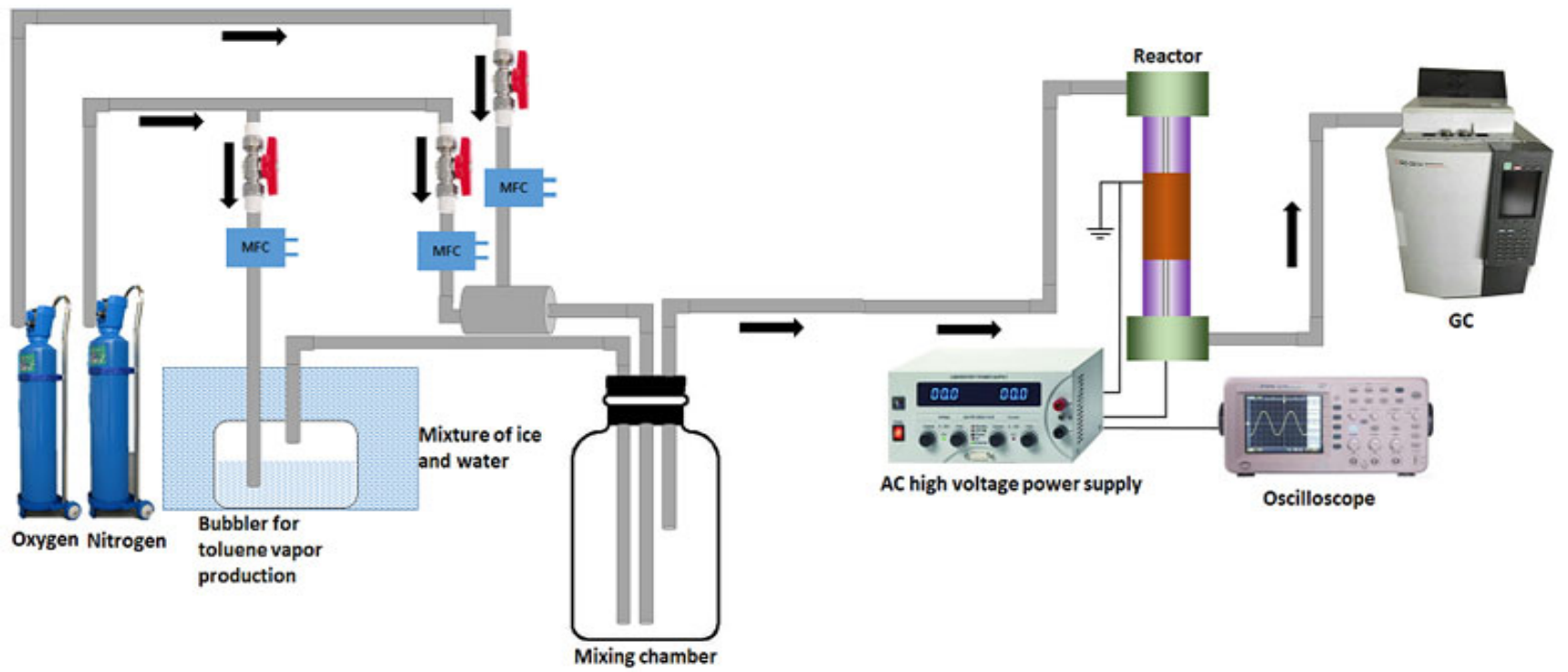

Fig. 1. Schematic illustration of the experimental setup. 
mixture $\left(10 \% \mathrm{H}_{2}\right.$ by volume) was switched on, and the catalyst was heated to $700^{\circ} \mathrm{C}$ at a rate of $10^{\circ} \mathrm{C} \mathrm{min}{ }^{-1}$. The $\mathrm{H}_{2}$ consumption was monitored by a thermal conductivity detector (TCD).

\section{In Situ FT-IR Study}

In situ FT-IR spectra was recorded using a Nicolet 6700 spectrometer equipped with a mercury-cadmium-telluride (MCT) detector cooled by liquid nitrogen. The catalyst was pretreated at $300^{\circ} \mathrm{C}$ in high-purity $\operatorname{Ar}\left(100 \mathrm{~mL} \mathrm{~min}^{-1}\right)$ for $60 \mathrm{~min}$, cooled to room temperature, then toluene- $-\mathrm{N}_{2}-\mathrm{O}_{2}$ mixture (100 ppm toluene, $\mathrm{N}_{2}: \mathrm{O}_{2}=20 \%: 80 \%$ ) was introduced into the IR cell. The infrared spectra of toluene adsorption were collected with a resolution of $2 \mathrm{~cm}^{-1}$ and 64 scans in the region of $650-4000 \mathrm{~cm}^{-1}$.

\section{Identification of Organic Byproducts on the Catalyst Surface}

The organic byproducts on the catalyst surface were extracted by $\mathrm{CS}_{2}$ solution (chromatographic grade) at the condition of ultrasonic vibration for $120 \mathrm{~min}$. Then filtered with a $0.22 \mu \mathrm{m}$ filter membrane, and analyzed by a GC-MS (QP2010; Shimadzu) with Rtx-5MS capillary column. The column temperature was firstly maintained at $40^{\circ} \mathrm{C}$ for $2 \mathrm{~min}$, then increased to $220^{\circ} \mathrm{C}$ with a rate of $6^{\circ} \mathrm{C} \mathrm{min}{ }^{-1}$, and maintaining for $5 \mathrm{~min}$. MS identification was conducted using the NIST 08 databank (NIST/EPA/NIH Mass Spectral Library).

\section{RESULTS AND DISCUSSION}

\section{Catalytic Activity Evaluation}

The results of toluene removal efficiency and $\mathrm{CO}_{2}$ selectivity were showed in Fig. 2. The toluene removal efficiency was only $47 \%$ under the condition of NTP, while it significantly increased as the various catalysts were packed into the plasma system. The toluene removal efficiency caused by SBA-15, $3 \% \mathrm{FeO}_{x} / \mathrm{SBA}-15,2 \% \mathrm{FeO}_{x}-1 \% \mathrm{AgO}_{y} / \mathrm{SBA}-15$ increased by
$48.9 \%, 50.3 \%, 51.3 \%$ respectively. $\mathrm{CO}_{2}$ selectivity had no significant change over the SBA-15, while it was increased by $11 \%$ over the $3 \% \mathrm{FeO}_{x} / \mathrm{SBA}-15$ and $17 \%$ over the $2 \% \mathrm{FeO}_{x}-$ $1 \% \mathrm{AgO}_{y} / \mathrm{SBA}-15$ catalyst. This suggests that the catalytic activity of composite metal oxides is higher than that of single component. In view of the reason, Wang et al. (2015) and Chen et al. (2011) found that the catalysts loaded with Ag could form stronger $\pi$-complex and had higher adsorption capacity for toluene, resulting remain time in the plasma system was increased. Ag could also weaken the Fe-O bond and increase the lattice oxygen mobility (Scirè et al., 2001). On the other hand, Ag reoxidation was readily accomplished by the transfer of adsorbed oxygen from $\mathrm{FeO}_{x}$, which could contribute to maintain the good performance for toluene degradation in the plasma system. These results indicate that the interaction between $\mathrm{Ag}$ and $\mathrm{Fe}$ species could increase the catalyst activity, and consequently improve the performance of the plasma-catalytic degradation of toluene.

\section{In Situ FT-IR Spectroscopy of Toluene Adsorption}

In situ FT-IR technology could provide continuous monitoring for VOCs adsorption over the catalyst surface (Augugliaro et al., 1999). Therefore, in situ FT-IR spectroscopy of toluene adsorption over the catalyst surface was carried out under the condition of $80 \% \mathrm{~N}_{2}+20 \% \mathrm{O}_{2}$ (Fig. 3). The band of the toluene adsorption appeared on all the catalysts: $1392,1460,1495$ and $1608 \mathrm{~cm}^{-1}$ characteristics of aromatic ring $\mathrm{C}=\mathrm{C}$ stretching vibration (Li et al., 2007); 2879, 2928 $\mathrm{cm}^{-1}$ characteristics of C-H vibrations of methyl (Maira et al., 2001; Eby et al., 2012); $3031 \mathrm{~cm}^{-1}$ characteristic of C-H vibration of aromatic ring (Maira et al., 2001). Also, the new adsorption bands at 1120 , assigned to terpene $\mathrm{OH}$ stretching (Das et al., 2014), and 1167, assigned to ester C-O stretching (Long et al., 2011; Yang et al., 2013), appeared on the surface of catalyst loaded with Ag. This indicates that the toluene oxidation on the catalyst surface was improved due to the Ag introduction. However, deep oxidization was not accomplished at room temperature, and as a result, it
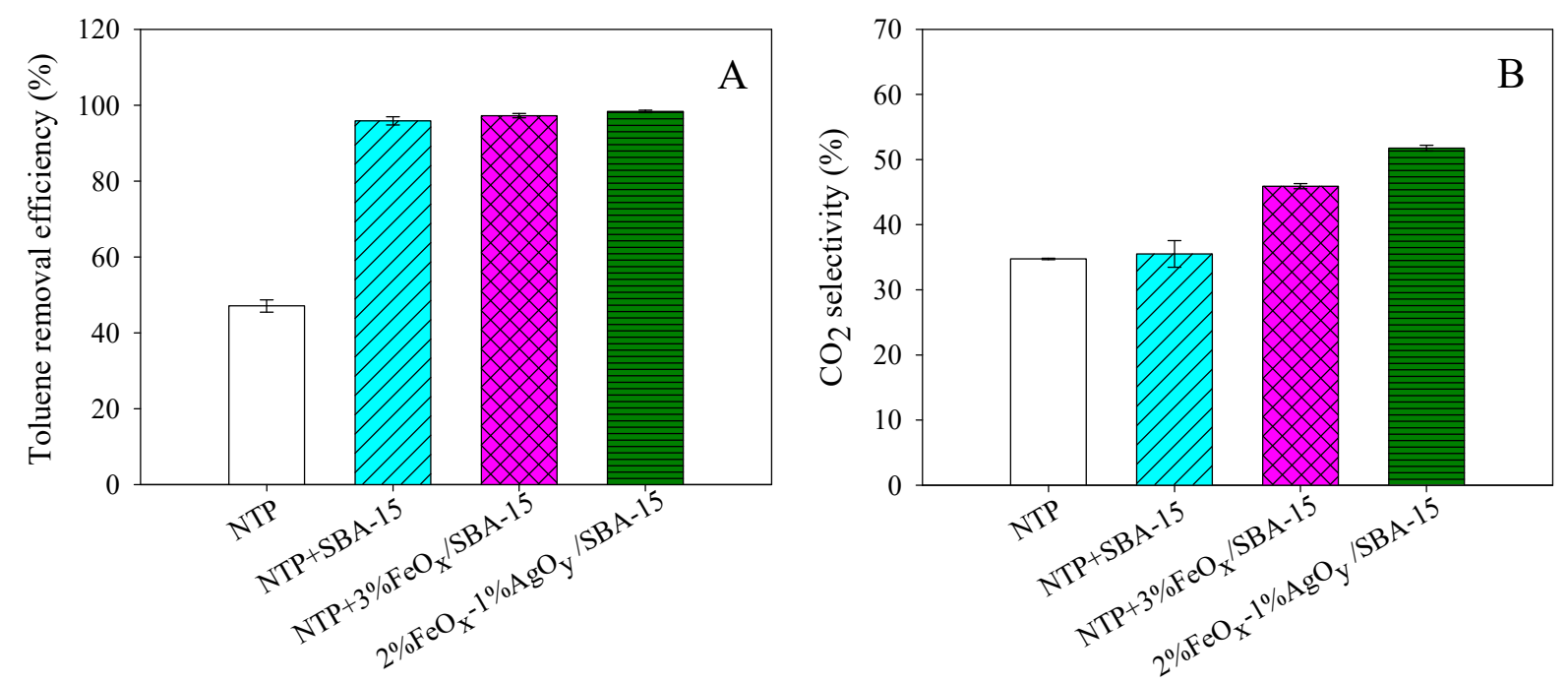

Fig. 2. Effect of catalyst on (A) toluene removal efficiency and (B) $\mathrm{CO}_{2}$ selectivity (Initial concentration of toluene: 100 ppm, SED: $767 \mathrm{~J} \mathrm{~L}^{-1}$ ). 


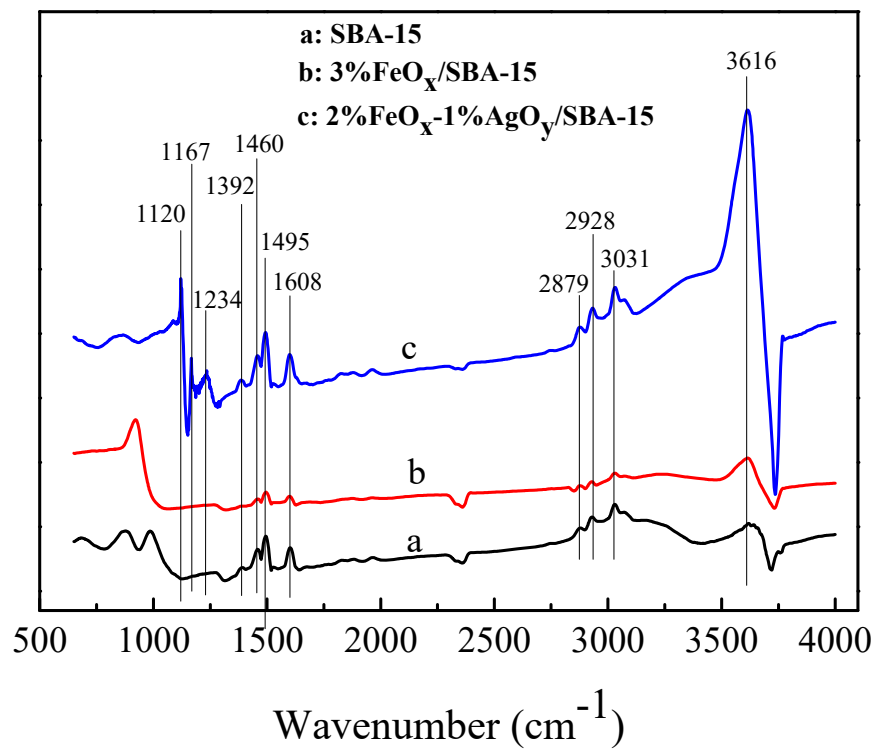

Fig. 3. In situ FT-IR spectroscopy of toluene adsorption over the catalyst surface (Initial concentration of toluene: 100 ppm, background gas: $80 \% \mathrm{~N}_{2}+20 \% \mathrm{O}_{2}$ ).

produced unexpected terpenoid and ester. There was no significant difference for the absorption band at $3616 \mathrm{~cm}^{-1}$, characteristic ascribed to $\mathrm{OH}$ stretching (Li et al., 2011a, b), on the SBA- 15 and $3 \% \mathrm{FeO}_{x} / \mathrm{SBA}-15$, while this peak intensity increased on the surface of $2 \% \mathrm{FeO}_{x}-1 \% \mathrm{AgO}_{y} / \mathrm{SBA}-15$ catalyst. Those indicate that $\mathrm{Ag}$ incorporation could promote the generation of derivatives related to $\mathrm{OH}$ (Li et al., 2011b), which might be beneficial to toluene degradation on the surface of catalyst (Fig. 2).

\section{Analysis of the Toluene Oxidation Residues}

Byproducts on the catalyst surface were monitored by GC-MS (Fig. 4). The results show that the benzaldehyde, 4-methyl-2-pentanone had relatively high amounts on the SBA-15 surface, while they significantly decreased when Fe and $\mathrm{Ag}$ were introduced. This suggests that $\mathrm{Fe}$ and $\mathrm{Ag}$ loading could promote toluene oxidation in the process of NTP combined catalyst, which agreed with the results of $\mathrm{CO}_{2}$ selectivity (Fig. 2).

\section{Catalyst Characterization}

In order to study the relationship between catalyst structure and toluene removal efficiency, the catalysts were characterized by XRD (Fig. 5), SEM (Fig. 6) and $\mathrm{H}_{2}-\mathrm{TPR}$ (Fig. 7).

\section{$X R D$}

The results of low-angle XRD patterns (Fig. 5(a)) show the characteristic peaks, (100), (110), and (200), of mesoporous material and indicates that highly ordered 2D-hexagonal mesoporous structure of SBA-15 was retained after loading Fe and Ag. Fig. 5(b) shows the wide-angle XRD patterns of SBA-15, $3 \% \mathrm{FeO}_{x} / \mathrm{SBA}^{-15}$ and $2 \% \mathrm{FeO}_{x}-1 \% \mathrm{AgO}_{y} / \mathrm{SBA}-15$ catalysts. The $\mathrm{Fe}_{2} \mathrm{O}_{3}$ and $\mathrm{Fe}_{3} \mathrm{O}_{4}$ diffraction peaks were clearly observed when $3 \% \mathrm{Fe}$ was loaded on SBA-15. However, they disappeared while $\mathrm{Ag}_{2} \mathrm{O}$ and $\mathrm{Ag}$ diffraction peaks were observed as Ag species incorporation. This tendency might be caused by the formation of amorphous iron, or the fact that the particles of iron oxidation are highly dispersed on the support material with the such low amount Fe loading, resulting in the exceedance of detection limit with XRD.

$\mathrm{Ag}$ could serve as a reservoir for gas-phase toluene because of the $\pi$ bond formation with toluene (Huang et al., 2015). $\mathrm{Ag}^{+}$is better at adsorbing toluene and weakening its $\mathrm{C}=\mathrm{C}$ bond (Trinh et al., 2015; Qin et al., 2016). This could promote the toluene transformation from gas phase to the catalyst surface, then decrease the toluene degradation in the gas phase by the NTP, and improve the $\mathrm{CO}_{2}$ selectivity during the toluene plasma-catalyst oxidation (Fig. 2). In addition, the $\mathrm{Ag}^{+}$on the catalyst is essential for high catalytic activity of CO oxidation (Zhang et al., 2013), which might be the reason for high $\mathrm{CO}_{2}$ selectivity in the process of toluene degradation in the combined Ag-Fe NTP system.

\section{SEM}

The catalyst morphology was observed by SEM (Fig. 6). Some small granules appeared and evenly dispersed on the SBA-15 surface when the $3 \%$ Fe was loaded. However, the amount of particles decreased as $1 \% \mathrm{Ag}$ incorporating, and the particles were smaller than those on the surface of $3 \% \mathrm{FeO}_{x} / \mathrm{SBA}-15$. In order to study the morphology of the particles on the $2 \% \mathrm{FeO}_{x}-1 \% \mathrm{AgO}_{y} / \mathrm{SBA}-15$ surface, SEM of $2.5 \% \mathrm{FeO}_{x}-0.5 \% \mathrm{AgO}_{y} / \mathrm{SBA}-15$ and $1.5 \% \mathrm{FeO}_{x}-1.5 \% \mathrm{AgO}_{y} /$ SBA-15 were also provided (Figs. 6(d) and 6(e)). There were no large particles on the $2.5 \% \mathrm{FeO}_{x}-0.5 \% \mathrm{AgO}_{y} / \mathrm{SBA}-$ 15 catalyst, but some particles newly appeared on the $1.5 \% \mathrm{FeO}_{x}-1.5 \% \mathrm{AgO}_{y} / \mathrm{SBA}-15$ surface, and their size was even larger than those on the $3 \% \mathrm{FeO}_{x} / \mathrm{SBA}-15$. This suggests that the particles on the $2 \% \mathrm{FeO}_{x}-1 \% \mathrm{AgO}_{y} / \mathrm{SBA}-15$ surface were the $\mathrm{Ag}$ compounds, and the diffusion of $\mathrm{FeO}_{x}$ particles were promoted by Ag incorporating. These results might benefit for the improvement of $\mathrm{FeO}_{x}$ catalytic activity. 


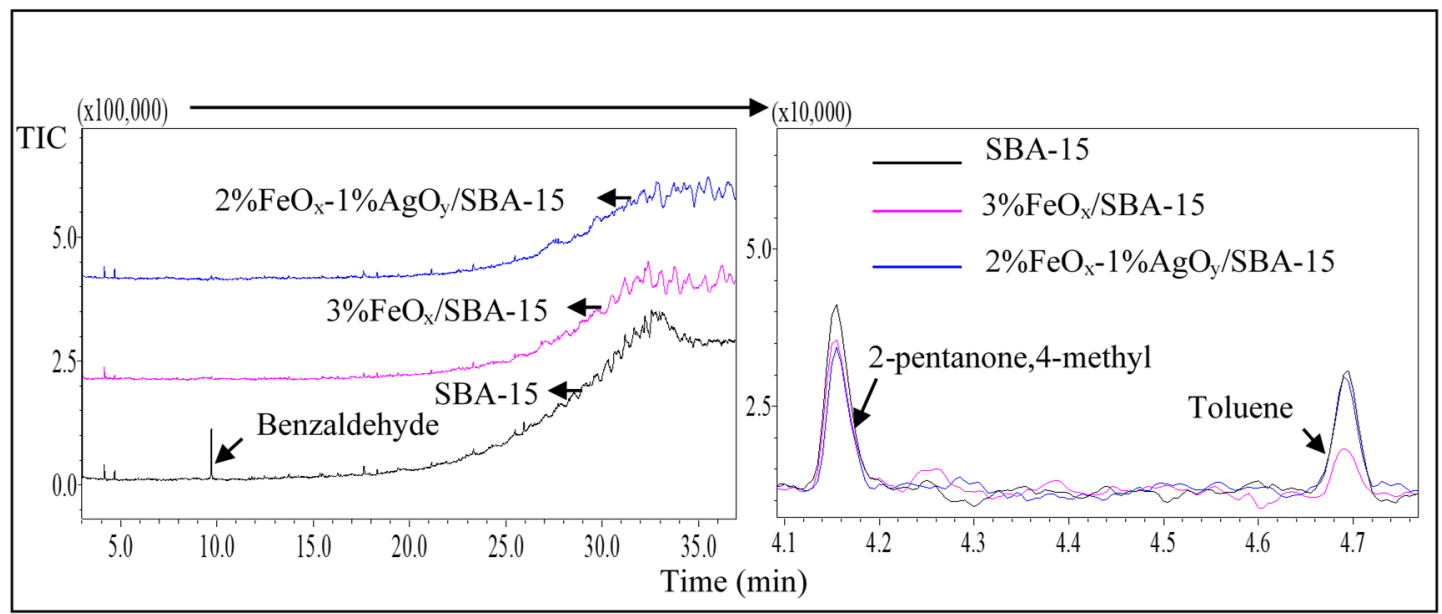

Fig. 4. GC-MS spectrum of organic by-products from toluene decomposition on the catalyst surface.
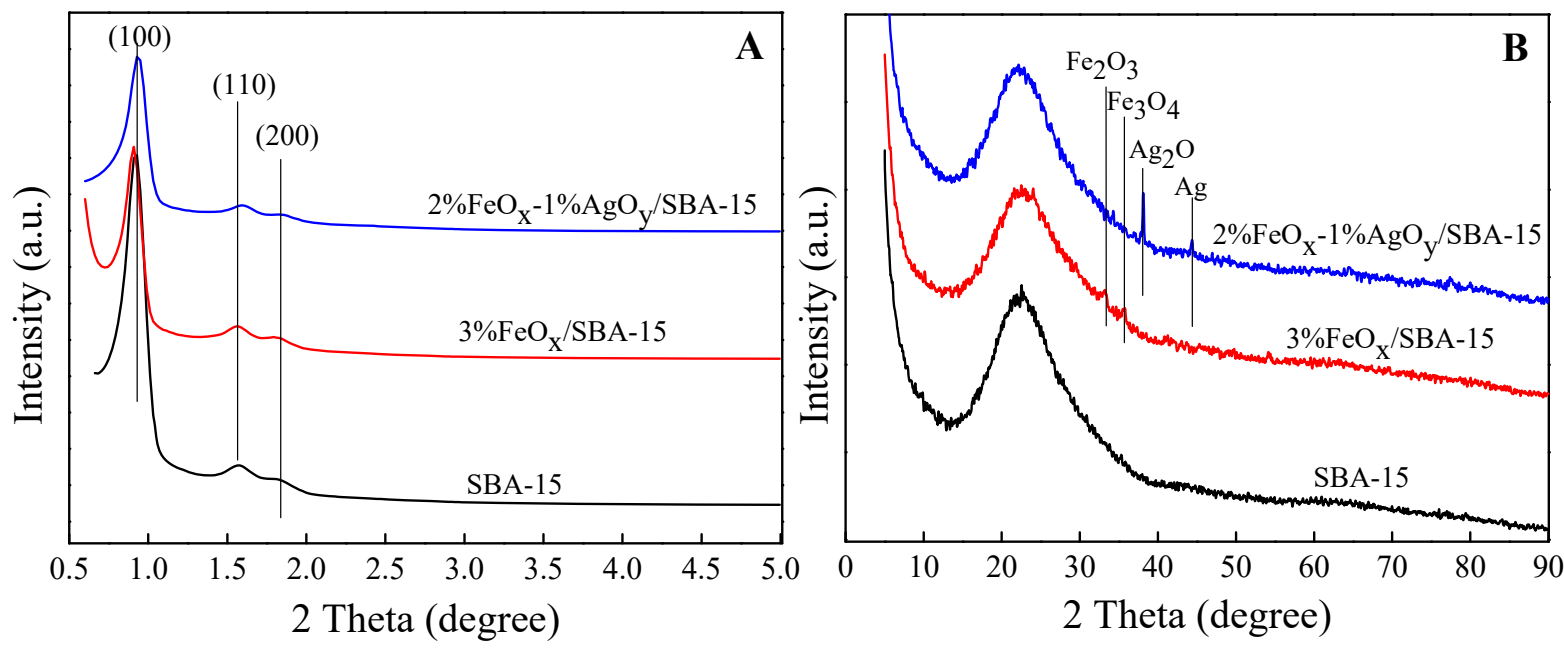

Fig. 5. (A) Low-angle, (B) wide-angle XRD patterns of catalysts.

\section{$\mathrm{H}_{2}-\mathrm{TPR}$}

The catalytic property of catalyst was determined by the reducibility, which could be measured by $\mathrm{H}_{2}$-TPR (Gogoi et al., 2020). Fig. 7 presents the $\mathrm{H}_{2}$-TPR profiles of different catalysts. The reduction peak at $126^{\circ} \mathrm{C}$ was observed in all catalysts and had no obvious change after $\mathrm{Fe}$ and $\mathrm{Ag}$ incorporation, which was attributed to the $\mathrm{H}_{2}$ consumption by SBA-15. For the $3 \% \mathrm{FeO}_{x} / \mathrm{SBA}-15$ catalyst, the lowtemperature reduction peak $\left(325^{\circ} \mathrm{C}\right)$ and a shoulder peak $\left(438^{\circ} \mathrm{C}\right)$ could be attributed to the reduction of $\mathrm{Fe}_{2} \mathrm{O}_{3} \rightarrow$ $\mathrm{Fe}_{3} \mathrm{O}_{4} \rightarrow \mathrm{Fe}$ (Long et al., 2011; Zhang et al., 2012a). In order to study the reduction of $\mathrm{Ag}, \mathrm{H}_{2}$-TPR profile of $3 \% \mathrm{AgO}_{y} / \mathrm{SBA}-15$ was also carried out. Only one reduction peak could be observed at $110^{\circ} \mathrm{C}$ assigned to the reduction of $\mathrm{Ag}^{+}$to $\mathrm{Ag}$ (Chen et al., 2011), while it did not appear on others catalysts. Therefore, all the reduction peaks in the $2 \% \mathrm{FeO}_{x}-1 \% \mathrm{AgO}_{y} / \mathrm{SBA}-15$ could be assigned to the reduction of $\mathrm{FeO}_{x}$. At the same time, all reduction peaks shifted to the lower temperature at the catalyst of $2 \% \mathrm{FeO}_{x}-1 \% \mathrm{AgO}_{y} / \mathrm{SBA}-$ 15 than $3 \% \mathrm{FeO}_{x} / \mathrm{SBA}-15$. This suggests that the reducibility of $\mathrm{FeO}_{x}$ was promoted, indicating that the lattice oxygen mobility was higher in $2 \% \mathrm{FeO}_{x}-1 \% \mathrm{AgO}_{y} / \mathrm{SBA}-15$ (Jin et al.,
2013). Therefore, $2 \% \mathrm{FeO}_{x}-1 \% \mathrm{AgO}_{y} / \mathrm{SBA}-15$ catalyst showed the better performance for $\mathrm{CO}_{2}$ selectivity in the plasma system (Fig. 2(b)).

\section{Pathways of Toluene Degradation}

Based on the results of toluene removal efficiency, analysis of organic byproducts, and in situ FT-IR spectroscopy of toluene adsorption, the mechanism of toluene degradation is proposed (Fig. 8). Toluene decomposition in plasmaassisted catalysis could be described to direct plasma reaction and plasma-catalytic surface reaction.

For the direct plasma reaction, it contains direct electron attack or indirect reactions between VOC molecules and gas-phase radicals. As we all know, there are a large number of high-energy electrons in the plasma system, which could react with $\mathrm{O}_{2}, \mathrm{H}_{2} \mathrm{O}$ and $\mathrm{N}_{2}$ in the outlet gas as follows (R4$\mathrm{R} 10$ ), and form gas-phase radicals $\left(\mathrm{O} \cdot, \mathrm{OH} \cdot\right.$ and $\left.\mathrm{N}_{2}{ }^{*}\right)$ (BlinSimiand et al., 2009; Yu et al., 2010; Abdelaziz et al., 2013; Liang et al., 2013; Chung et al., 2019). The high-energy electron and the activity radical could induce the toluene degradation (ring opening, oxidation) in gas phase, and formed $\mathrm{CO}_{2}$ and $\mathrm{H}_{2} \mathrm{O}$. 

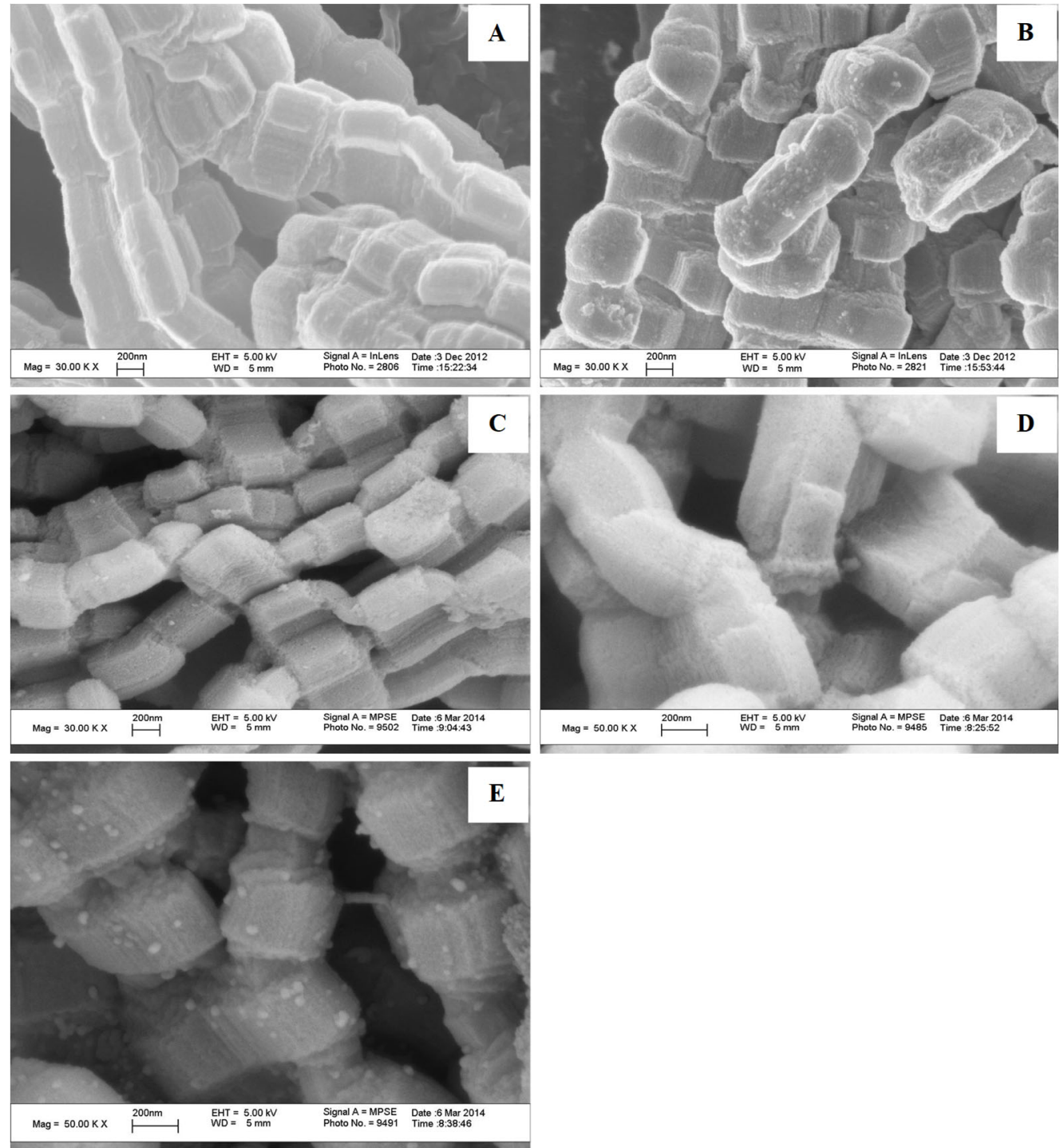

$\mathbf{E}$

Fig. 6. SEM images of various catalysts. (A) SBA-15, (B) $3 \% \mathrm{FeO}_{x} / \mathrm{SBA}-15$, (C) $2 \% \mathrm{FeO}_{\mathrm{x}}-1 \% \mathrm{AgO}_{\mathrm{y}} / \mathrm{SBA}-15$, (D) $2.5 \% \mathrm{FeO}-$ $0.5 \% \mathrm{AgO}_{\mathrm{y}} / \mathrm{SBA}-15$, (E) $1.5 \% \mathrm{FeO}_{\mathrm{x}}-1.5 \mathrm{AgO}_{\mathrm{y}} / \mathrm{SBA}-15$.

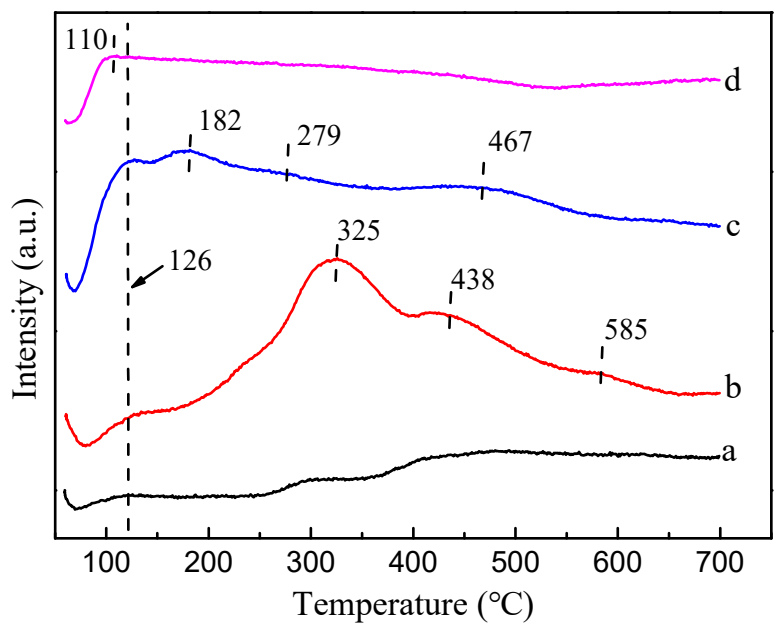

Fig. 7. $\mathrm{H}_{2}-\mathrm{TPR}$ profiles of different $\mathrm{Fe}$ and $\mathrm{Ag}$ loading catalysts (a: SBA-15, b: $3 \% \mathrm{FeO}_{\mathrm{x}} / \mathrm{SBA}-15$, c: $2 \% \mathrm{FeO}_{\mathrm{x}}-$ $1 \% \mathrm{AgO}_{\mathrm{y}} / \mathrm{SBA}-15$, d: $\left.3 \% \mathrm{AgO}_{\mathrm{y}} / \mathrm{SBA}-15\right)$.

$$
\begin{aligned}
& \mathrm{e}+\mathrm{O}_{2} \rightarrow \mathrm{e}+\mathrm{O} \cdot\left({ }^{3} \mathrm{P}\right)+\mathrm{O} \cdot\left({ }^{3} \mathrm{P}\right) \\
& \mathrm{e}+\mathrm{O}_{2} \rightarrow \mathrm{e}+\mathrm{O} \cdot\left({ }^{1} \mathrm{D}\right)+\mathrm{O} \cdot\left({ }^{1} \mathrm{D}\right) \\
& \mathrm{e}+\mathrm{H}_{2} \mathrm{O} \rightarrow \mathrm{OH} \cdot+\mathrm{H} \cdot \\
& \mathrm{e}+\mathrm{H}_{2} \mathrm{O} \rightarrow \mathrm{O} \cdot+2 \mathrm{H} \cdot \\
& \mathrm{H}_{2} \mathrm{O}+\mathrm{O} \cdot\left({ }^{1} \mathrm{D}\right) \rightarrow 2 \mathrm{OH} \cdot \\
& \mathrm{N}_{2}+\mathrm{e} \rightarrow \mathrm{N}_{2} *+\mathrm{e} \\
& \mathrm{N}_{2} *+\mathrm{O}_{2} \rightarrow \mathrm{O}\left({ }^{3} \mathrm{P}\right)+\mathrm{O}\left({ }^{3} \mathrm{P}\right)+\mathrm{N}_{2}
\end{aligned}
$$

When the SAB-15 was introduced into the plasma system, toluene could be adsorbed on the catalyst surface, and oxidized into the benzaldehyde, then experienced through an opening of aromatic ring to form 4-methyl-2-pentanone, and further oxidized into $\mathrm{CO}_{2}$ and $\mathrm{H}_{2} \mathrm{O}$ by $\mathrm{O} \cdot$ and $\cdot \mathrm{OH}$. As the 


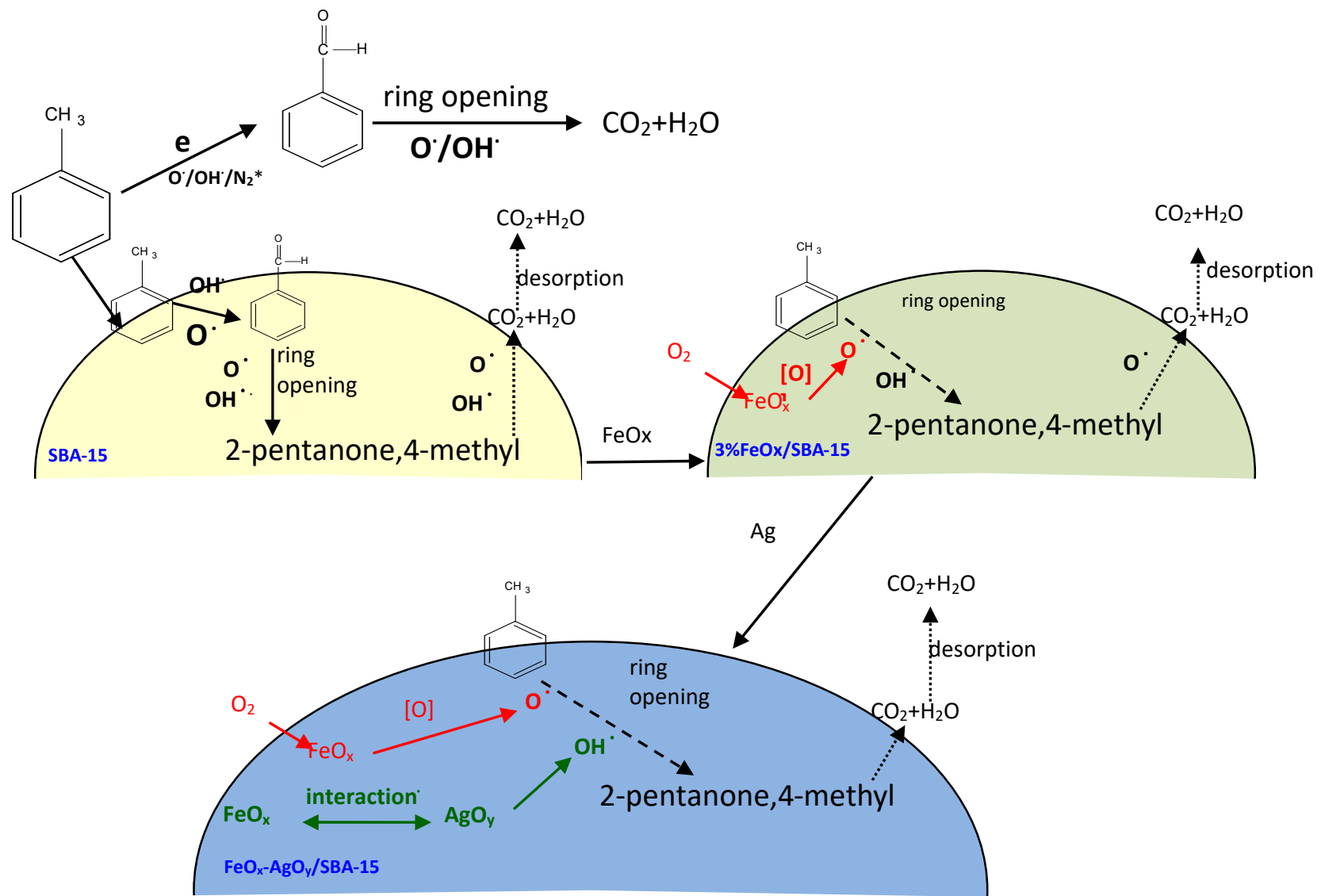

Fig. 8. Pathway of toluene degradation in the plasma-assisted catalyst system.

$3 \% \mathrm{Fe}$ was loaded on the SBA-15 surface, the $\mathrm{O}_{2}$ in the gas phase could also be adsorbed on the catalyst surface via facile inter-conversion between $\mathrm{Fe}^{2+}$ and $\mathrm{Fe}^{3+}$ states, which could lead to the formation of free radical of $\mathrm{O} \cdot$. The generated $\mathrm{O}$. was then transported to the toluene on the catalyst surface, leading to a fast opening of its aromatic ring, and the further oxidization to $\mathrm{CO}_{2}$ which finally desorbed from catalyst surface into gas phase. When $\mathrm{Ag}$ was incorporated, the amount of the $\cdot \mathrm{OH}$ was significantly improved (Fig. 3) because of the interaction between $\mathrm{FeO}_{x}$ and $\mathrm{AgO}_{y}$. As discussed above, a fast opening of the aromatic ring happened and led to the formation 4-methyl-2-pentanone, which then was mineralized to $\mathrm{CO}_{2}$, and finally desorbed from catalyst surface into gas phase. On the other hand, toluene could also be adsorbed on the catalyst surface because of the $\pi$ bond formation between $\mathrm{Ag}$ and toluene, then oxidized by oxygen from $\mathrm{FeO}_{x}$ adsorbed, subsequently, mineralized into the $\mathrm{CO}_{2}$ and $\mathrm{H}_{2} \mathrm{O}$. At the same time, Ag reoxidation was readily accomplished by the transfer of adsorbed oxygen from $\mathrm{FeO}_{x}$. Therefore, the reaction of toluene oxidation could be sustained. Meanwhile, the consumed oxygen species on the catalysts could be replenished by either gas-phase oxygen, or active oxygen species generated during the plasma process. The consumed oxygen in the gas phase would alleviate the effect of oxygen's negative electrons on the process of toluene removal.

\section{Evaluation of Catalyst Stability}

The stability of SBA- $15,3 \% \mathrm{FeO}_{x} / \mathrm{SBA}-15$ and $2 \% \mathrm{FeO}_{x}-$
$1 \% \mathrm{AgO}_{y} / \mathrm{SBA}-15$ catalysts (Fig. 9), during toluene plasmacatalytic oxidation, was assessed at room temperature and atmospheric pressure. It was observed that toluene removal proceeded stably during the first $19 \mathrm{~h}$ for all the catalysts. After that, the toluene removal efficiency decreased in SBA-15 and $3 \% \mathrm{FeO}_{x} / \mathrm{SBA}-15$, while the $2 \% \mathrm{FeO}_{x}-1 \% \mathrm{AgO}_{y} / \mathrm{SBA}-15$ catalyst was perfectly stabilized over the period of $37 \mathrm{~h}$ for toluene conversion. This suggests that the interaction between $\mathrm{Ag}$ and $\mathrm{Fe}$ improved the stability of catalyst.

Meanwhile, toluene removal efficiency shows the variation from $80 \%$ to $100 \%$ in $\mathrm{SBA}-15$ and $3 \% \mathrm{FeO}_{x} / \mathrm{SBA}-15$, which might be due to an accumulation of water molecules on the catalyst surface (Lu et al., 2014). However, this phenomenon did not appear at the $2 \% \mathrm{FeO}_{x}-1 \% \mathrm{AgO}_{y} / \mathrm{SBA}-15$ combined NTP system. This suggests that adding Ag improved the catalyst's capability of resisting water molecules, which was very important to improve catalytic activity of the catalyst.

The XRD of the catalysts for different reaction times were compared to study structural stability of the catalysts (Fig. 10). Three characteristic peaks, (100), (110), and (200), characterizing the mesoporous material with 2D-hexagonal structure, were clearly identified, and no other diffraction peak was observed. This indicates that highly ordered 2Dhexagonal mesoporous structure of SBA-15 has not been altered by the plasma, although SBA- 15 and $3 \% \mathrm{FeO}_{x} / \mathrm{SBA}-$ 15 had suffered slight deactivation during the toluene plasma-catalytic oxidation. 


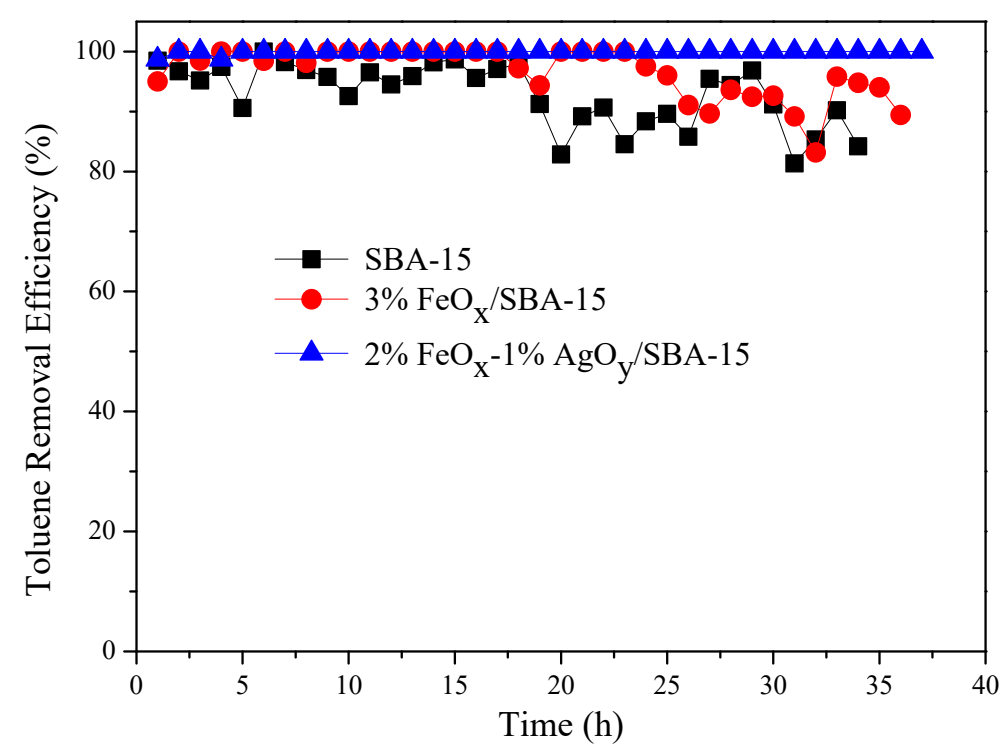

Fig. 9. Toluene removal over different catalysts as a function of time (Initial concentration of toluene: 100 ppm; feed gas: $\left.80 \% \mathrm{~N}_{2}+20 \% \mathrm{O}_{2}\right)$.

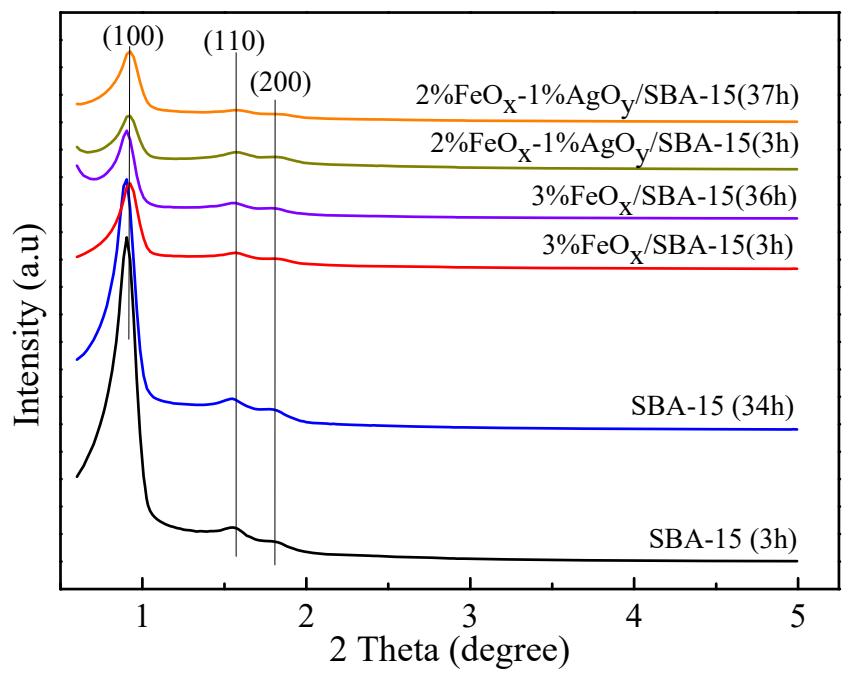

Fig. 10. The low-angle XRD patterns of different catalysts after reaction in plasma at $767 \mathrm{~J} \mathrm{~L}^{-1}$.

\section{CONCLUSIONS}

Combining $3 \% \mathrm{FeO}_{x} / \mathrm{SBA}-15$ and $2 \% \mathrm{FeO}_{x}-$ $1 \% \mathrm{AgO}_{y} / \mathrm{SBA}-15$ catalysts with NTP drastically improved their toluene removal efficiency and $\mathrm{CO}_{2}$ selectivity and markedly reduced the production of organic intermediates. Of these two catalysts, $2 \% \mathrm{FeO}_{x}-1 \% \mathrm{AgO}_{y} / \mathrm{SBA}-15$ exhibited higher $\mathrm{CO}_{2}$ selectivity and catalyst stability when introduce into nonthermal plasma, which was probably due to the reduced size and the increased dispersion and reducibility of the $\mathrm{FeO}_{x}$ particles following the incorporation of $\mathrm{Ag}$. In addition, $\mathrm{Ag}$, existing in the form of $\mathrm{Ag}_{2} \mathrm{O}$ and $\mathrm{Ag}$ particles on the catalyst surface, adsorbed toluene and promoted the production of hydroxyl groups, thus improving the reductive activity of the $\mathrm{FeO}_{x}$. These findings can be used to further optimize the use of $\mathrm{FeO}_{x}$ and $\mathrm{AgO}_{x}$ in plasma-assisted catalyst systems for toluene degradation.

\section{ACKNOWLEDGMENT}

This work was supported by the National Natural Science Foundation of China (Grant Nos. 51508245 and 51808269) and the Jiangxi Province Science and Technology Funds for Young Scholars (20192BAB213020). We appreciate Jinbao $\mathrm{He}$, Mr. Rex Howitson for checking the English language. We would also thank the anonymous reviewers for the valuable comments.

\section{REFERENCES}

Abdelaziz, A.A., Seto, T., Abdel-Salam, M. and Otani, Y. (2013). Influence of nitrogen excited species on the destruction of naphthalene in nitrogen and air using surface dielectric barrier discharge. J. Hazard. Mater. 246-247: 26-33. 
Augugliaro, V., Coluccia, S., Loddo, V., Marchese, L., Martra, G., Palmisano, L. and Schiavello, M. (1999). Photocatalytic oxidation of gaseous toluene on anatase $\mathrm{TiO}_{2}$ catalyst: Mechanistic aspects and FT-IR investigation. Appl. Catal., B 20: 15-27.

Blin-Simiand, N., Pasquiers, S., Jorand, F., Postel, C. and Vacher, J. (2009). Removal of formaldehyde in nitrogen and in dry air by a DBD: Importance of temperature and role of nitrogen metastable states. J. Phys. D: Appl. Phys. 42: 122003.

Chen, D., Qu, Z.P., Shen, S.J., Li, X.Y., Shi, Y., Wang, Y., $\mathrm{Fu}, \mathrm{Q}$. and $\mathrm{Wu}$, J.J.(2011). Comparative studies of silver based catalysts supported on different supports for the oxidation of formaldehyde. Catal. Today 175: 338-345.

Chung, W.C., Mei, D.H., Tu, X. and Chang, M.B. (2019). Removal of VOCs from gas streams via plasma and catalysis. Catal. Rev. 61: 270-331.

Das, D., Datta, D.B. and Bhattacharya, P. (2014). Simultaneous dyeing and finishing of silk fabric with natural color and itaconic acid. Clothing Text. Res. J. 32: 93-106.

Eby, T., Gundusharma, U., Lo, M., Sahagian, K., Marcott, C. and Kjoller, K. (2012). Reverse engineering of polymeric multilayers using AFM-based nanoscale IR spectroscopy and thermal analysis. Spectrosc. Eur. 24: $18-21$.

Gogoi, P., Nagpure, A.S., Kandasamy, P., Satyanarayana, C. and Thirumalaiswamy, R. (2020). Insights into the catalytic activity of $\mathrm{Ru} / \mathrm{NaY}$ catalysts for efficient $\mathrm{H}_{2}$ production through aqueous phase reforming. Sustainable Energy Fuels doi: 10.1039/C9SE00797K.

Huang, R., Lu, M.J., Wang, P.T., Chen, Y.D., Wu, J.L., Fu, M.L., Chen, L.M. and Ye,D.Q. (2015). Enhancement of the non-thermal plasma-catalytic system with different zeolites for toluene removal. RSC Adv. 5: 72113-72120.

Jiang, N., Hu, J., Li, J., Shang, K.F., Lu, N. and Wu, Y. (2016). Plasma-catalyticdegradation of benzene over AgCe bimetallic oxide catalysts using hybrid surface/packedbed discharge plasmas. Appl. Catal., B 184: 355-363.

Jiang, N., Zhao, Y.H., Qiu, C., Shang, K.F, Lu, N., Li, J., $\mathrm{Wu}, \mathrm{Y}$. and Zhang, Y. (2019). Enhanced catalytic performance of $\mathrm{CoO}_{\mathrm{x}}-\mathrm{CeO}_{2}$ for synergetic degradation of toluene in multistage sliding plasma system through response surface methodology (RSM). Appl. Catal., B 259: 118061.

Jin, M.S., Kim, J.H., Kim, J.M., Jeon, J.K., Jurng, J., Bae, G.N. and Park, Y.K. (2013). Benzene oxidation with ozone over MnOx/SBA-15 catalysts. Catal. Today 204: 108-113.

Li, C.M., Liu, J., Shi, X., Yang, J. and Yang, Q.H (2007). Periodic mesoporous organosilicas with 1, 4diethylenebenzene in the mesoporous wall: synthesis, characterization, and bioadsorption properties. J. Phys. Chem. C 111: 10948-10954.

Li, J.Q., Feng, Y., Mo, S.P., Liu, H., Chen, Y.F. and Yang, J. (2016). NanodendriticPlatinum supported on $\gamma$-alumina for complete benzene oxidation. Part. Part. Syst. Char. 33: 620-627.

Li, X.Y., Zhu, Z.R., Zhao, Q.D. and Liu, S.M. (2011a). FT-
IR study of the photocatalytic degradation of gaseous toluene over UV-irradiated $\mathrm{TiO}_{2}$ microballs: enhanced performance by hydrothermal treatment in alkaline solution. Appl. Surf. Sci. 257: 4709-4714.

Li, X.Y., Zou, X.J., Qu, Z.P., Zhao, Q.D. and Wang, L.Z. (2011b). Photocatalytic degradation of gaseous toluene over Ag-doping $\mathrm{TiO}_{2}$ nanotube powder prepared by anodization coupled with impregnation method. Chemosphere 83: 674-679.

Li, Y.Z., Fan, Z.Y., Shi, J.W., Liu, Z.Y. and Shangguan, W.F. (2014). Post plasma-catalysis for VOCs degradation over different phase structure $\mathrm{MnO}_{2}$ catalysts. Chem. Eng. J. 24: 251-258.

Liang, W.J., Ma, L., Liu, H. and Li, J. (2013). Toluene degradation by non-thermal plasma combined with a ferroelectric catalyst. Chemosphere 92: 1390-1395.

Long, L.P., Zhao, J.G., Yang, L.X., Fu, M.L., Wu, J.L., Huang, B.C. and Ye, D.Q. (2011). Room temperature catalytic ozonation of toluene over $\mathrm{MnO}_{2} / \mathrm{Al}_{2} \mathrm{O}_{3}$. Chinese J. Catal. 32: 904-916. (in Chinese)

Lu, M., Huang, R., Wu, J., Fu, M., Chen, L. and Ye, D. (2015). On the performance and mechanisms of toluene removal by $\mathrm{FeOx} / \mathrm{SBA}-15$-assisted non-thermal plasma at atmospheric pressure and room temperature. Catal. Today 242: 274-286.

Lu, M.J, Huang, R., Wang, P.T., Chen, L.M., Wu, J.L., Fu, M.L., Wen, W., Huang,B.C. and Ye, D.Q. (2014). Plasma-catalytic oxidation of toluene on $\mathrm{Mn}_{\mathrm{x}} \mathrm{O}_{\mathrm{y}}$ at atmospheric pressure and room temperature. Plasma Chem. Plasma Process. 34: 1141-1156.

Lu, W.J., Abbas, Y.W., Mustafa, M.F., Pan, C. and Wang, H.T. (2019). A review on application of dielectric barrier discharge plasma technology on the abatement of volatile organic compounds. Front. Environ. Sci. Eng. 13: 30.

Maira, A., Coronado, J., Augugliaro, V., Yeung, K., Conesa, J. and Soria, J. (2001). Fourier Transform Infrared Study of the Performance of Nanostructured $\mathrm{TiO}_{2}$ Particles for the Photocatalytic Oxidation of Gaseous Toluene. $J$. Catal. 202: 413-420.

Pangilinan, C. D. C., Kurniawan, W., Salim, C. and Hinode, H. (2016). Effect of $\mathrm{Ag} / \mathrm{TiO}_{2}$ catalyst preparation on gasphase benzene decomposition using non-thermal plasma driven catalysis under oxygen plasma. React. Kinet. Mech. Catal. 117: 103-118.

Qin, C.H., Dang, X.Q., Huang, J.Y., Teng, J.J. and Huang, X.M. (2016). Plasma-catalytic oxidation of adsorbed toluene on $\mathrm{Ag}-\mathrm{Mn} / \gamma-\mathrm{Al}_{2} \mathrm{O}_{3}$ : Comparison of gas flowthrough and gas circulation treatment. Chem. Eng. J. 299: $85-92$.

Qin, Y., Qu, Z.P., Dong, C., Wang, Y. and Huang, N. (2019). Highly catalytic activity of Mn/SBA-15 catalysts for toluene combustion improved by adjusting the morphology of supports. J. Environ. Sci. 76: 208-216.

Scirè, S., Minicò, S., Crisafulli, C. and Galvagno, S. (2001). Catalytic combustion of volatile organic compounds over group IB metal catalysts on $\mathrm{Fe}_{2} \mathrm{O}_{3}$. Catal. Commun. 2: 229-232.

Stasiulaitiene, I., Martuzevicius, D., Abromaitis, V., Tichonovas, M., Baltrusaitis, J., Brandenburg, R., 
Pawelec, A. and Schwock, A. (2016). Comparative life cycle assessment of plasma-based and traditional exhaust gas treatment technologies. J. Cleaner Prod. 112: 18041812.

Trinh, Q. H., Lee, S. B. and Mok, Y. S. (2015). Removal of ethylene from air stream by adsorption and plasmacatalytic oxidation using silver-based bimetallic catalysts supported on zeolite. J. Hazard. Mater. 285: 525-534.

Wang, W.Z., Wang, H.L., Zhu, T. L.and Fan, X. (2015). Removal of gas phase low-concentration toluene over Mn, Ag and Ce modified HZSM-5 catalysts by periodical operation of adsorption and non-thermal plasma regeneration. J. Hazard. Mater. 292: 70-78.

Yang, H.G., Deng, J.G., Liu, Y.X., Xie, S.H., Wu, Z.X. and Dai, H.X. (2016). Preparation and catalytic performance of $\mathrm{Ag}, \mathrm{Au}, \mathrm{Pd}$ or Pt nanoparticles supported on 3DOM $\mathrm{CeO}_{2}-\mathrm{Al}_{2} \mathrm{O}_{3}$ for toluene oxidation. J. Mol. Catal. A: Chem. 414: 9-18.

Yang, Y., Zhang, W., Wu, J.L., Fu, M.L., Chen, L.M. and Huang, B.C. (2013). In situ infrared spectroscopic studies of plasma-catalytic degradation of toluene. Acta Sci. Circumst. 33: 3138-3145. (in Chinese)

Yu, L., Tu, X., Li, X.D., Wang, Y., Chi, Y. and Yan, J.H. (2010). Destruction of acenaphthene, fluorene, anthracene and pyrene by a de gliding arc plasma reactor. J. Hazard. Mater. 180: 449-455.

Zhang, H.L., Tang, C.J., Sun, C.Z., Qi, L., Gao, F., Dong, L. and Chen, Y. (2012a). Direct synthesis, characterization and catalytic performance of bimetallic Fe-Mo-SBA-15 materials in selective catalytic reduction of $\mathrm{NO}$ with $\mathrm{NH}_{3}$. Microporous Mesoporous Mater. 151: 44-55.

Zhang, W.W., Qu, Z.P., Li, X.Y., Wang, Y., Ma, D. and Wu, J.J. (2012b). Comparison of dynamic adsorption/desorption characteristics of toluene on different porous materials. $J$. Environ. Sci. 24: 520-528.

Zhang, X.D., Qu, Z.P., Yu, F.L. and Wang, Y. (2013). Hightemperature diffusion induced high activity of SBA-15 supported Ag particles for low temperature $\mathrm{CO}$ oxidation at room temperature. J. Catal. 297: 264-271.

Zhu, X.B., Liu, S.Y., Cai, Y.X., Gao, X., Zhou, J.S., Zheng, C.H. and Tu, X. (2016). Post-plasma catalytic removal of methanol over $\mathrm{Mn}-\mathrm{Ce}$ catalysts in an atmospheric dielectric barrier discharge. Appl. Catal., B 183: 124-132.

Received for review, September 18, 2019 Revised, November 29, 2019 Accepted, November 30, 2019 